\title{
INTERNET AMONG STUDENTS - FROM MATHEMATICAL RATIONALITY TO UNREALITY
}

\section{Tarik Bazdalić ${ }^{1}$ \\ Vehbi Ramaj \\ Sead Rešić \\ Maid Omerović}

Faculty of Education Travnik, Bosnia and Herzegovina

Business Faculty, University of "Haxhi Zeka"

Department of Mathematics, Faculty of Sciences, University of Tuzla, Bosnia and Herzegovina

Faculty of Education Travnik, Bosnia and Herzegovina

\author{
Original scientific paper
}

Received: 08.02.2018

Accepted: 19.03.2018

\begin{abstract}
Today's modern lifestyle and contemporary ways of working and gaining knowledge in schools and universities could not be imagined without high technology - the Internet. Simply said, internet entered all the pores of contemporary life in big style. If used rationally, internet can truly facilitate work in all spheres of modern man's life. However, internet also has a dark side which comes to light if its excessive use becomes internet addiction, or internet infatuation. We reached this hypothesis through everyday contact with students in class as well as our colleagues teachers. In order to determine if and to what extent internet addiction among students exists, we applied a generic method, that is, we used survey as one of techniques of research. The survey was conducted in October of academic year 2017/2018. Sample of 79 students was selectedfrom first and fourth grades in Secondary school "Muhsin Rizvic" in Kakanj.
\end{abstract}

Keywords: scientific achievements, the Internet, free time, school subject matter, textbooks, Mathematics.

\section{INTRODUCTION}

Modern lifestyle and working conditions, as well as communication models, can not be imagined without the use of internet. "Internet was invented by accident, during the cold war when the American army needed to establish communication and exchange of experiences between American scientists hired by the US army. Some years afterwards, internet was still limited to universities, but the development of personal computers enabled its true explosion" (Kukić, 2004). Today, internet has penetrated all pores of human life.

${ }^{1}$ Correspondence to:

Sead Rešić, Department of Mathematics, Faculty of Sciences, University of Tuzla

Šabana Zahirovića 10, Tuzla, B\&H

Phone: +38761 101230

E-mail: sresic@hotmail.com 
It has become inevitable as means of communication, doing everyday chores in companies, it helps students better understand and gain more knowledge in various school subjects, aids in different life situations, provides information of all kinds. Simply said, internet has become one of basic needs in human life.

However, besides all mentioned benefits, internet can become very harmful or even lethal if approached incorrectly. This applies, first and foremost, to unconfirmed and unreliable information which can be found on the Internet. The reason why such information is available is the fact that anyone can write various information even without having knowledge about the subject matter or even if their intentions are not benevolent. So, considering that certain information was written without scientific proof, it is not always possible to differentiate between correct and incorrect information, especially if the subject matter is not very well known to readers. Because of this, there is a great danger of inappropriate use of internet and deliberate placement of incorrect information to lead the reader to wrong conclusions and complete disorientation, followed by offer of salvation from hopelessness through joining different socially harmful and dangerous groups of people.

What is also beyond understanding is the mass use of certain internet sites where people, without any obvious need and justification, voluntarily enter their personal information and photographs without even considering the fact that someone may use them for dark purposes. This is especially true for young people, mostly high school and university students. It can be said that young people spend most of their time visiting such sites where they communicate discussing meaningless things. "With the exception of email, where users identify themselves, nobody online knows who they are talking to - male, female, where they live. Is this invention going to make us lose our identity in a new space? Is computer technology start to dominate us, instead of it being vice versa?" (Giddens, 2001).

Some high school and university students were noticed to use the Internet to gain knowledge in all subjects, including Mathematics, and all that without their textbooks and notebooks. Students are encouraged to do this by their teachers, which can not be a good thing for either. Students get the feeling that they do not have to pay attention or participate in class, which results in a great number of absences, especially when it comes to university students, and creates a feeling of uselessness in teachers.
"Will electronic media destroy books?" (Giddens, 2001). Where does this world of high technology lead us? Does internet lead young educated people in a state ofinfatuation which can at the end cause psychological disorders with unforeseeable consequences followed by inability for socially valuable work and independent life?

All these questions can not be answered precisely at this moment.

The subject of this research is to evaluate how much students use the Internet and whether its use has reached the state of addiction to internet, that is, infatuation by internet, or if this is a mathematical reality.

\section{AIM AND TASKS}

The main goal of this research is to determine how much students use the Internet in learning school subject matter as well as in everyday life, and whether the use of internet is so extensive that students became addicted to it.

The subject of this research and its formulated aim give us the following research tasks:

1. To determine whether students spend most of their free time sitting by the computer and surfing the Internet.

2. To determine whether students use only internet for learning school subjects, including Mathematics, and neglect other learning aids - textbooks and notebooks.

3. To determine whether students, while surfing the Internet, visit sites with various quasi-scientific theories which are completely opposite from knowledge they gained in school and whether they believe everything they find online.

4. To determine how the use of internet negatively impacts students, but also how it has positive effects in realization of teaching content (Selimović, Rodić \& Selimović, 2013).

\section{HYPOTHESES}

From the aim and tasks of research mentioned above, zero hypothesis is formed:

$\mathrm{H} 0$ : Students use the Internet rationally for electronic communication and acquiring information in everyday life which is urgently needed or cannot be gained any other way. In order to master school subjects, students only need their textbook and notebook, and there is no need for internet, especially in Mathematics. 
The main hypothesis stands against zero hypothesis: $\mathrm{H}$ : Students use the Internet excessively, whether they really need it to gain information or not. They spend all their free time online. They use only internet as learning aid to master school subjects and neglect completely notebooks and textbooks considering them unnecessary. They accept all information as reliable, even that which is completely opposite from the knowledge they gained in their school years. All this leads to main hypothesis stating that students became addicted to internet, or even infatuated by it.

\section{RESEARCH}

In order to secure quality survey conditions, while gaining reliable empirical data, characteristics and size of the sample were taken into account. Sample consisted of students in two fist and two fourth grades in "Muhsin Rizvić" secondary school in Kakanj, a total of 79 students - examinees. The sample was deliberately made of first and fourth gradesin order to examine whether there is deviation between generations in the degree of using the Internet. When it comes to sample size, it is medium size, but the accent of the survey is not in the number of examinees, but rather in results of the research.

In order to make the survey good, successful and adequate, it had to fulfil the following conditions:

- Contributing to examinees' high motivation;

- Asking examinees to provide necessary information which cannot be gained any other way;

- Being optimally long and not demanding a lot of time to complete;

- Satisfying esthetic qualities (arrangement and attractiveness);

- Not prying into personal matters;

- Guaranteeing anonymity;

- Being clear;

- Having questions in the survey formulated clearly, definitely, short, unambiguous, understandable without unnecessary words, or unknown and unusual terminology;

- Without suggestive questions.

General information required from all examinees on the survey was gender, class and average grade in Mathematics.

The questionnaire type was closed and consisted of nine questions, with three possible answers offered for each one. The answers were graded from 1 to 3 points without examinees' knowledge of grading so as to avoid suggestible answers.
Offered answers graded with one point were formulated in favor of zero hypothesis. Those answers graded with two points indicate border between zero and main hypothesis. Finally, answers graded with three points were formulated in favor of the main hypothesis.

Survey questions and possible answers with awarded points are shown as follows:

1. In your opinion, what is the biggest achievement of modern civilization?

a) Wireless communication between people (2)

b) Internet (3)

c) Radio and television (1)

2. How do you spend most of your free time?

a) Partly using internet, partly for a hobby. (2)

b) Internet is my favorite way to spend free time. (3)

c) I spend most of my free time walking, doing sports activities, going to sports matches, socializing with my friends, etc. (1)

3. How would you feel if you spent a longer time without access to internet?

a) I would feel like I lost one of my senses. (3)

b)I would hardly feel anything. (1)

c) I would feel unusual at the beginning, but it would stop being a problem in time. (2)

4. How much time do you spend surfing the Internet daily?

a) I visit internet only when I need information or to send and receive emails. (1)

b)I surf the Internet at least 3 hours a day, mostly Facebook, internet games or other lighter reading. (3)

c) Every day I visit the Internet to see if I received an email or to read news from different areas of interest, spending 30 minutes at most. (2)

5. Do you use internet to master school subjects?

a) No, textbooks, notebooks and following the classes are enough for me. (1)

b) Yes, internet has become a necessary means in conquering school subjects, so I do not need textbooks at all, while I use notebooks only for subject topics. (3)

c) Occasionally (2)

6. Do you use internet to learn Mathematics?

a) Occasionally (2)

b) No, textbooks, notebooks and following the classes are enough for me. (1)

c) Yes, internet is the simplest and fastest means for gaining knowledge in Mathematics. (3)

7. Mathematics homework has a task for which you need a pattern you cannot remember. What will you do? 
a) I will look for it in a mini collection of Mathematical patterns. (1)

b) I will call one of my friends and ask them. (2)

c) I will look for it on the Internet. (3)

8. Do you believe everything you find on the Internet, such as theory that "Earth is flat", "Gravity does not exist", "the atomic bomb does not exist", etc.?

a) Of course I do. (3)

b) After learning this, I am starting to doubt what we learn in school. (2)

c) I believe only those theories which do not contradict what I learn in school. (1)

9. If you read online that someone saw aliens, photographed them and posted those photos on the Internet, would you believe it?

a) I would accept it with a grain of salt. (2)

b) Of course not. (1)

c) Yes, I would. (3)

Adding points for all offered answers to nine questions was formulated to result in a sum not smaller than 9 or greater than 27 . This range of possible sums of points in this questionnaire gave a scale based on which every examinee was grouped as follows:

1. Examinees whose sum of points was 9-16 were considered to use the Internet rationally, i.e. only when they need it and exhibit no internet addiction.

2. Examinees whose sum of points was 17-20 were considered to exhibit increased appetite for internet, but still were not addicts.

3. Examinees whose sum of points was 21-27 were considered completely addicted to the Internet, or infatuated by it.

\section{RESULTS}

For analysis and interpretation of results, percentage procedure was used as a quick and simple way of statistical analysis.

So, after the survey was completed on a sample of 79 examinees in total, from first and fourth grades, and after the questionnaire was reviewed and analyzed, the results are shown in the following summary table:

Table 1 Demonstration of internet addiction

\begin{tabular}{ccccccc}
\hline & \multicolumn{2}{c}{ First grade } & \multicolumn{2}{c}{ Fourth grade } & \multicolumn{2}{c}{ Total } \\
\cline { 2 - 7 } & $\mathrm{f}$ & $\%$ & $\mathrm{f}$ & $\%$ & $\mathrm{f}$ & $\%$ \\
\hline Not addicted to internet & 5 & 10 & 4 & 13 & 9 & 12 \\
Increased use of internet & 20 & 41 & 15 & 50 & 35 & 44 \\
Addicted to (infatuated by) internet & 24 & 49 & 11 & 37 & 35 & 44 \\
Total & 49 & 100 & 30 & 100 & 79 & 100 \\
\hline
\end{tabular}

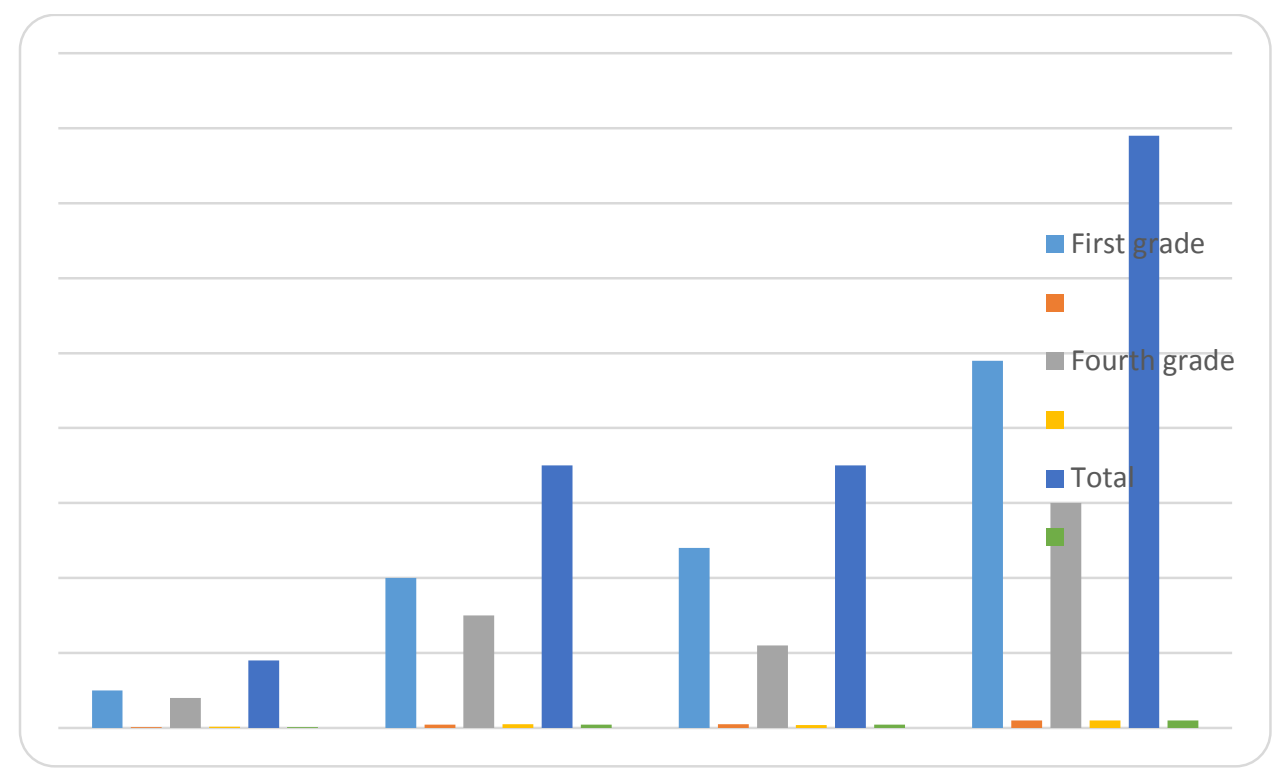

Graph 1 Demonstration of internet addiction 


\section{CONCLUSION}

Based on gained results of this research, it can be concluded that, according to previously determined criteria, approximately only $1 / 7$ of representative sample is not addicted to the Internet.

Approximately $3 / 7$ of representative sample can be considered as not yet addicted to the Internet, but still uses it excessively.

Finally, approximately $3 / 7$ of representative sample can be considered infatuated by the Internet, because their use of it has become so excessive that they are addicted.

Comparing results of research between first and fourth grades, what can be seen is that the younger generation (first grades) is about $1 / 3$ more susceptible to the influence of the Internet than the older generation (fourth grades). This difference between generations can be explained through the fact that the older generation spent more time "socializing" through the Internet so that they became oversaturated. However, this could be the topic of another research.
Based on the acquired results of this research, it can be said that the main hypothesis was completely confirmed although, comparing zero and main hypothesis, the result are in favor of the main hypothesis. That is, according to previously determined criteria, significant part of the sample (3/7) gave results that characterize examinees as excessively using internet, but still are not internet addicts.

Even though research results are generally discouraging, the above-mentioned conclusion regarding differences between generations gives hope because it can be expected that older generations will use the Internet more rationally without the attribute "infatuated".

\section{REFERENCES}

Selimović, H., Rodić, N. \& Selimović, N. (2013).Metodologija istraživanja. Univerzitet u Travniku, Edukacijski fakultet

Kukić, S. (2004). Sociologija teorije društvene strukture. Sarajevo: Sarajevo Publishing

Giddens, A. (2001). Banja Luka: CID Podgorica-Romanov 